\title{
O PROGRAMA INSTITUCIONAL DE BOLSAS DE INICIAÇÃo À dOCÊNCIA (PIBID) E AS RELAÇões PÚBLICO/PRIVAdAS NA EDUCAÇÃo SUPERIOR
}

\author{
THE INSTITUTIONAL PROGRAM OF TEACHING INITIATION BAGS (PIBID) \\ AND PUBLIC/PRIVATE RELATIONS IN HIGHER EDUCATION \\ EL PROGRAMA INSTITUCIONAL DE BOLSAS DE INICIACIÓN A LA DOCENCIA \\ (PIBID) Y PÚBLICO/PRIVADO EM LA EDUCACIÓN SUPERIOR
}

\section{RESUMO}

\author{
Margarita Victoria Rodríguez ${ }^{1}$ \\ Jorismary Lescano Severino ${ }^{1}$ \\ Caroline Maciel ${ }^{1}$ \\ Silvia Helena Andrade de Brito ${ }^{1}$
}

O objeto deste trabalho é o Programa Institucional de Bolsas de Iniciação à Docência (PIBID), sendo seu objetivo analisar a regulamentação e a aprovação de bolsas e subprojetos do PIBID, sob a perspectiva da relação público/privada na educação superior. Para tal, o procedimento metodológico utilizado foi a análise da legislação do Programa, bem como os dados disponibilizados nos relatórios do PIBID. Isto posto, é evidenciado que, embora pese o caráter neoliberal na organização do Programa, com relação à parceria público/privada, o maior volume de bolsas e projetos aprovados ainda estavam com o setor público, até 2014. Algumas tensões são apresentadas nessa perspectiva, mas elas também evidenciam a precarização da educação superior privado e a característica assistencialista do programa.

PALAVRAS-CHAVE: PIBID. Público/privado. Ensino superior.

\begin{abstract}
The objective of this work is the Institutional Program of Initiatives for Teaching (PIBID), whose objective is to analyze the regulation and approval of PIBID scholarships and subprojects from the perspective of the public / private relation in higher education. For this, the methodological procedure used was the analysis of the Program's legislation, as well as the data made available in the PIBID reports. This shows that, despite the neoliberal nature of the program's organization, in relation to the public / private partnership, the largest volume of approved scholarships and projects were still with the public sector until 2014. Some tensions are presented in this perspective, But they also highlight the precariousness of private higher education and the program's characteristic.
\end{abstract}

KEYWORDS: PIBID. Public/private. Higher education.

\section{RESUMEN}

El objeto de este trabajo es el Programa Institucional de Bolsas de Iniciación a la Docencia (PIBID), su objetivo es analizar la reglamentación y la aprobación de becas e sub-proyectos del PIBID, bajo la perspectiva de la relación público/privada en la educación superior. Para tanto, el procedimiento metodológico utilizado consistió en el análisis de la legislación del Programa, así como los datos disponibilizados en los informes del PIBID. De acuerdo a lo expuesto, se evidencia que a pesar del carácter neoliberal que sustenta la organización del Programa, con relación a la asociación público/privada, el mayor volumen de becas e proyectos aprobados aún se encontraban en el sector público, hasta 2014. Algunas tensiones se presentan en esta perspectiva, pero ellas también evidencian la precarización de la educación superior privada y la característica asistencialista del Programa.

\footnotetext{
${ }^{1}$ Universidade Federal de Mato Grosso do Sul - E-mail: margarita.victoria.rodriguez@ gmail.com - ORCID: http://orcid.org/0000-0003-3075-9336 Submetido em: 15-11-2016 / Aceito em: 25-01-2017 / Publicado em: 27-01-2017.

\begin{tabular}{l|l|l|l|l|l|l} 
(C) Rev. Inter. Educ. Sup. & Campinas, SP & v.3 & n.1 & p.27-45 & jan./abr. 2017 & ISSN 2446-9424 \\
\hline
\end{tabular}
}


PALABRAS CLAVE: PIBID. Público/privada. Educación superior.

\section{INTRODUÇÃO}

O Programa Institucional de Bolsas de Iniciação à Docência (PIBID), voltado para o fortalecimento da formação inicial, em especial para a sua maior articulação com a educação básica, foi criado em 2007, no âmbito do Ministério da Educação (MEC), e implementado pela Coordenadoria de Aperfeiçoamento de Pessoal de Nível Superior (CAPES) e o Fundo Nacional de Desenvolvimento da Educação (FNDE), conforme a Portaria Normativa n. 38, de 12 de dezembro de 2007, e regulamentado pelo Decreto n. 7219, de 24 de junho de 2010. A finalidade do Programa é " [...] fomentar a iniciação à docência, contribuindo para o aperfeiçoamento da formação de docentes em nível superior e para a melhoria de qualidade da educação básica pública brasileira" (BRASIL, 2010). O presente artigo, tendo como foco o PIBID, traz para a análise o respetivo programa sob a perspectiva da relação público/privada na educação superior.

Nessa perspectiva, este trabalho tem como objetivo analisar o Programa sob a ótica da relação público/privada na educação superior. Para tanto, busca-se compreender as diretrizes de apoio aos subprojetos do PIBID, bem como a concessão de incentivos para a realização do mesmo, sob a forma de bolsas, correlacionando tais variáveis aos interesses e incentivos de ampliação da educação superior privada no país.

Ressalte-se que o referido Programa é uma das diversas estratégias implementadas durante o governo do Presidente Luiz Inácio Lula da Silva (2003-2010), no contexto das políticas educacionais que tiveram como objetivo contribuir com a melhoria da qualidade da formação inicial e continuada dos docentes da educação básica, bem como estabelecer uma maior aproximação das instituições escolares da educação básica com as instituições formadoras de professores. Ressalte-se que tais políticas estavam contidas nas atribuições da CAPES após as mudanças realizadas no ano de 2005, quando esta agência assumiu a coordenação das políticas voltadas à formação de professores. Estas iniciativas tiveram continuidade durante o governo de Dilma Vana Rousseff (2011-2016).

A questão de formação de professores durante os governos de Lula da Silva e Dilma Roussef foi um tema que esteve no centro do debate, dado que os estudos apontavam à falta de docentes qualificados para atuar no ensino médio, e nas últimas séries do ensino fundamental. No ano de 2007 o Conselho Nacional de Educação divulgou o Relatório produzido pela Comissão Especial instituída para estudar medidas que visassem a superar o déficit docente no Ensino Médio (CNE/CEB), intitulado Escassez de professores no Ensino Médio: propostas estruturais e emergenciais (RUIZ; RAMOS; HINGEL, 2007).

O Relatório apontava diversos problemas relacionados com a falta de professores. Para tanto, mencionava a pesquisa da Organização Mundial do Trabalho, a qual destacava que o Brasil era um dos países que pagava os salários mais baixos entre os 38 estudados; além disso, frisava o escasso interesse dos jovens em cursar carreiras do magistério. 
Outro aspecto sinalizado pelo Relatório foi a carência de docentes formados em disciplinas como Química, Matemática e Biologia, chamando a atenção para o significativo número de vagas para os cargos de professores no ensino médio para essas áreas de conhecimento: faltam "[...] cerca de 235 mil professores para o Ensino Médio no país, particularmente nas disciplinas de Física, Química, Matemática e Biologia" (RUIZ; RAMOS; HINGEL, 2007, p. 9).

No documento os autores também apresentam uma série de soluções e proposições para atender os problemas registrados na pesquisa. Entre as propostas previstas para implementação a longo prazo, destacam-se as seguintes:

a) Constituir efetivamente um Sistema Nacional de Educação que articule os diferentes níveis de ensino no contexto dos entes federados;

b) Reestabelecer a Conferência Nacional de Educação para Todos, além das conferências em nível local e regional, com o intuito de propiciar o debate, intercâmbio de experiências e pesquisas relacionadas com a educação em geral, e mais especificamente com a formação de professores para procurar soluções a longo prazo em todos os níveis do ensino;

c) Instituir uma Política Nacional de Formação de Professores vinculada ao Sistema Nacional de Educação, para estabelecer estratégias e mecanismo de cooperação entre os entes federativos para atender a formação e qualificação dos professores, bem como criar Centros de Formação Continuada em todos os estados e nas cidades consideradas estratégicas nas distintas regiões do país;

d) Incentivar a participação permanente das instituições de educação superior, tanto na organização de cursos de licenciatura, como em cursos de formação continuada;

e) Instituir políticas públicas de formação de professores que abordem todos os conteúdos curriculares, com a elaboração de novos currículos que incorporem conteúdos inovadores. Dada a escassez de docentes nas áreas antes mencionadas, se propõe priorizar as Licenciaturas em Ciências da Natureza e Matemática;

f) Estabelecer o Piso Salarial para os Professores do Ensino Médio, associado à avaliação de desempenho, vinculado outrossim com a formação e dedicação em tempo integral.

Além destas medidas, o Relatório indicava soluções para atender os problemas planteados, e algumas destas propostas foram incorporadas nas políticas implementadas nos anos seguintes pelo governo federal. Entre tais iniciativas se encontra o PIBID.

Para a realização deste artigo, o procedimento metodológico adotado na pesquisa focou-se na análise da legislação que regula a implantação do Programa, bem como dos dados presentes no sítio da Coordenação de Aperfeiçoamento de Pessoal de Nível Superior (Capes), fundação do Ministério da Educação (MEC) que coordena o PIBID. Os referidos dados são parte da página denominada Relatórios e Dados (CAPES, 2016), onde são apresentadas algumas informações estatísticas e textuais a respeito da execução do Programa até 2014, assim como os critérios para definição da concessão de bolsas e recursos a subprojetos financiados pelo PIBID, em âmbito nacional. Tais elementos, bem como as fontes secundárias que permitiram refletir a respeito da história da expansão do ensino superior no país, foram aqueles utilizados nas análises presentes nesse trabalho. 
Como forma de organizar a discussão em torno da temática, o trabalho está disposto em dois tópicos. O primeiro apresenta as políticas neoliberais e seus desdobramentos, quando se apresenta o processo de expansão da educação superior e os incentivos voltados para a ampliação do ensino superior privado, nos governos já mencionados. Posteriormente, no segundo tópico, são considerados os critérios utilizados para a implantação de subprojetos e concessão de bolsas do PIBID, com foco na discussão a respeito da parceria público/privada na educação superior.

\section{O NEOLIBERALISMO E A EDUCAÇÃO SUPERIOR NO BRASIL}

O Brasil, nos anos de 1990, assim como outros países periféricos da América Latina, sofreu com a herança da neoliberalização iniciada nos países de capitalismo avançado. A renegociação da dívida externa com os setores financeiros acarretou o desenvolvimento de um novo projeto social, o qual visou estratégias para o fortalecimento da reestruturação produtiva, do livre comércio e do livre mercado, das privatizações, entre outras características desse regime de governo (HARVEY, 2008).

Segundo Leher (1999), a crise de endividamento dos países periféricos implicou na implementação de programas de estabilização e ajuste da economia latino-americana, desenhados pelo Banco Mundial (BM) e pelo Fundo Monetário Internacional (FMI). Nesse período, diante desta conjuntura permeada de transformações e contradições, criaram-se as condições para que o Brasil, assim como outros países, se subordinasse à nova ordem neoliberal, mediante a interferência dos setores financeiros.

Esse conjunto de transformações que levaram a mudanças em todas as esferas da vida social, também justificariam, na perspectiva neoliberal, a necessidade de reforma do Estado, apontado como elemento central para a superação da crise econômica, por meio da modernização da gestão das instituições governamentais. Nesse sentido, foi acelerado o processo de privatização de setores anteriormente sob direção estatal, como foi o caso de parte do setor energético e das telecomunicações, desregulamentando-se a economia e liberalizando-se unilateralmente o comércio exterior (SILVEIRA, 2009).

Dessa forma, observa-se que a perspectiva presente na formulação de uma parcela das políticas sociais instituídas no período de 1990, no Brasil, foram as orientações do neoliberalismo, construindo-se como diretrizes dessa ação seu caráter focal - os destinatários dessas políticas passaram a ser os "socialmente vulneráveis"; e o incentivo à participação de entes privados na execução das mesmas, por meio das parcerias público/privadas. Fato consubstanciado, por exemplo, na proposta do Projeto de Reconstrução Nacional $^{2}$, do

\footnotetext{
${ }^{2}$ Faz-se referência aqui ao Projeto de Reconstrução Nacional (que ficou conhecido como "Projetão"), parte do Plano Brasil Novo, do governo Fernando Collor de Mello (1990-1992), o qual visava a reforma do Estado. A partir do "Projetão", a presidência assume determinadas decisões políticas, visando atender as exigências dos organismos financeiros. Tal proposta determinava a redução do Estado, o fim da estabilidade dos funcionários

\begin{tabular}{l|l|l|l|l|l|l} 
(C) Rev. Inter. Educ. Sup. & Campinas, SP & v.3 & n.1 & p.27-45 & jan./abr. 2017 & ISSN 2446-9424
\end{tabular}
}


governo Collor (1990-1992), no Plano de Ação Imediata (PAI) ${ }^{3}$ do Governo Itamar Franco (1992-1994), ou ainda, a partir das alterações implementadas pelo Governo Fernando Henrique Cardoso ${ }^{4}$ (FHC). Por intermédio dessas políticas, os governos brasileiros ratificaram a tendência neoliberal, na medida em que adequam as estratégias de governo às exigências do mercado internacional (SILVEIRA, 2009).

No âmbito educacional, esse período significou uma fase liberal-modernizante, com a expectativa que a educação assegurasse o resgate da dívida social, mediante a vinculação com a produção nacional e sua competitividade com o setor internacional. Dessa forma, o ensino foi um importante mecanismo para adequar os parâmetros científicos e tecnológicos essenciais à Terceira Revolução Industrial e Tecnológica, colocando a educação a serviço da reprodução ampliada do capital (NEVES, 2005).

Essa situação se consubstancia a partir da promulgação da Lei de Diretrizes e Bases (LDB), de 20/12/1996, a qual referenda o novo patamar de escolarização exigido para a capacitação da força de trabalho brasileira, mediante os dois níveis de ensino (básico e superior), e na mesma medida cria novos cursos mais simplificados, na área da tecnologia, mediante a formação de tecnólogos (NEVES; FERNANDES, 2002).

Mesmo que a proposta desse novo projeto de governo determinasse que a educação e a saúde fossem setores de responsabilidade do Estado, e a LDB tenha definido a educação superior como fundamental na capacitação do trabalho complexo, a materialização das políticas neoliberais evidencia que o investimento público na educação destinou-se, em maiores proporções, à educação básica, especificamente para o ensino fundamental (BRASIL, 2013). Dessa forma, a expansão do ensino superior público não foi expressiva nesse período, e o elemento central da política para o setor foi o incentivo à expansão das empresas privadas. Em outros termos, em que pese a centralidade do Estado na gestão do Sistema Federal de Ensino Superior - do qual fazem parte as instituições de ensino superior (IES) públicas e privadas - e a presença do Estado no controle da avaliação de larga escala, tais elementos não geraram impedimentos para o avanço das IES privadas no país.

Neves e Fernandes (2002) confirmam tal situação a partir dos dados do Instituto Nacional de Estudos e Pesquisa (Inep) que, em 1990, registrava 37,6\% das matrículas dos cursos de graduação e pós-graduação nas instituições públicas, e 62,4\% nas instituições privadas. A concentração da oferta de ensino superior no setor privado se manteve até o final

públicos e a possibilidade de privatização das universidades federais, medidas que não foram adiante naquele momento devido à resistência de diversos setores, bem como devido ao afastamento de Collor em 1992 (SILVEIRA, 2009).

${ }^{3}$ O Plano previa: “[...] I) corte e maior eficiência de gastos; II) recuperação da receita tributária; III) fím da inadimplência de Estados e Municípios em relação às dívidas com a União; IV) controle e rígida fiscalização dos bancos estaduais; V) saneamento dos bancos federais; e VI) privatização" (SILVEIRA, 2009, p. 96). Essas iniciativas acabaram beneficiando o Sistema Financeiro Nacional, por meio do Programa de Estímulo à Reestruturação e ao Fortalecimento do Sistema Financeiro Nacional (Proer); e foram complementadas com a reforma monetária, que levou à transformação do cruzeiro em real.

${ }^{4}$ FHC desenvolveu políticas de estabilização econômica e equilíbrio das contas públicas, com a privatização e a liberalização comercial, visando a criação de infraestrutura adequada e um sistema financeiro ágil e moderno. Para tal, incentivou a administração gerencial, a recondução do Estado para a prestação de serviços básicos, em particular nos campos da educação e saúde (CARDOSO, 1995 apud SILVEIRA, 2009).

\begin{tabular}{l|l|l|l|l|l} 
(C) Rev. Inter. Educ. Sup. & Campinas, SP & v.3 & n.1 & p.27-45 & jan./abr. 2017
\end{tabular}

ISSN 2446-9424 
da década, como registra o Censo do ano 2000: 32,9\% das matrículas dos cursos de graduação estavam nas instituições públicas e $67,1 \%$ nas instituições privadas.

Nesse período, todas as regiões do Brasil sofreram com a interferência das políticas neoliberais na educação superior, por conseguinte, observou-se uma significante expansão da privatização do setor. Na região Norte, por exemplo, onde ainda prevalecia o ensino superior público, de 1994 a 1999 o ensino superior privado cresceu 8,4\%. No Sudeste, no mesmo período, ocorreu um crescimento de $72,7 \%$ para $76,8 \%$. No Sul, houve um crescimento de $48,3 \%$ para $64,7 \%$, e da mesma forma, na Região Centro-Oeste, em que a ampliação do setor passou de $56,6 \%$ para $64,3 \%$. O menor índice, embora também indicando crescimento da participação privada foi observado no Nordeste, que obteve um salto de 30,0\% para 32,0\% (NEVES; FERNANDES, 2002).

Na primeira década dos anos 2000, apesar de ter havido a continuidade das políticas neoliberais, algumas singularidades se manifestaram, principalmente em virtude da maior intervenção estatal em vários setores sociais, inclusive na educação superior. Sem romper com as premissas da neoliberalização, o período foi marcado por uma nova lógica de governo, de caráter marcadamente regulador.

Nesta perspectiva, mesmo que permanecesse articulado à lógica do mercado e sob preponderante atuação das instituições privadas, durante o governo do Luiz Inácio Lula da Silva, implantaram-se novas diretrizes para a oferta do ensino superior (NEVES, 2010). Assim, verifica-se iniciativas de intervenção do Estado, tanto na regulamentação de estratégias de inclusão de setores sociais que estavam fora do sistema, bem como mediante diferentes formas de financiamento - implementação de diferentes modalidades de bolsas, ampliação do Fundo de Financiamento Estudantil (Fies), construção de prédios, fornecimento de equipamentos, entre outros - e a criação de novas instituições públicas.

Com isso, verifica-se que há maior intervenção do Estado no campo da educação superior. Nessa perspectiva, diferentemente dos percentuais verificados no Censo da Educação Superior do ano de 2000, que indicavam significativa expansão do ensino superior privado, como apontaram Neves e Fernandes (2002), houve incremento do ensino superior público a partir do governo Lula da Silva. No período de 2005 a 2014, a rede pública do ensino superior cresceu $29,0 \%$, enquanto a rede privada teve um crescimento de $7,0 \%$, assim como indica a tabela 1 (INEP, 2005-2014).

Tabela 1. Evolução do número de instituições de educação superior, segundo categoria administrativa - Brasil - 2005-2014.

\begin{tabular}{|c|c|c|c|c|c|c|}
\hline \multirow[t]{2}{*}{ Ano } & \multirow[t]{2}{*}{ Total } & \multicolumn{4}{|c|}{ Pública } & \multirow[t]{2}{*}{ Privada } \\
\hline & & Total & Federal & Estadual & Municipal & \\
\hline 2005 & 2.165 & 231 & 97 & 75 & 59 & 1.934 \\
\hline 2006 & 2.270 & 248 & 105 & 83 & 60 & 2.022 \\
\hline 2007 & 2.281 & 249 & 106 & 82 & 61 & 2.030 \\
\hline \multicolumn{2}{|c|}{ (C) Rev. Inter. Educ. Sup. } & Campinas, SP & v. 3 & p.27-45 & abr. 2017 & $2446-9424$ \\
\hline
\end{tabular}




\begin{tabular}{l|c|c|c|c|c|c}
\hline $\mathbf{2 0 0 8}$ & 2.252 & 236 & 93 & 82 & 61 & 2.016 \\
\hline $\mathbf{2 0 0 9}$ & 2.314 & 245 & 94 & 84 & 67 & 2.069 \\
\hline $\mathbf{2 0 1 0}$ & 2.378 & 278 & 99 & 108 & 71 & 2.100 \\
\hline $\mathbf{2 0 1 1}$ & 2.365 & 284 & 103 & 110 & 71 & 2.081 \\
\hline $\mathbf{2 0 1 2}$ & 2.416 & 304 & 103 & 116 & 85 & 2.112 \\
\hline $\mathbf{2 0 1 3}$ & 2.391 & 301 & 106 & 119 & 76 & 2.090 \\
\hline $\mathbf{2 0 1 4}$ & 2.368 & 298 & 107 & 118 & 73 & 2.070 \\
\hline
\end{tabular}

Fonte: INEP (2005-2014).

Conforme a Tabela 1, verifica-se uma expansão das instituições de ensino superior em ambos os setores administrativos (público e privado). No entanto, diferente de períodos anteriores em que se deu uma ampliação mais significativa do ensino superior privado, no período de 2005 a 2014, os números apontam maior crescimento do ensino superior público.

Assinale-se, no entanto, que, embora durante esse período tenha ocorrido um significativo investimento e crescimento na criação de instituições públicas, é fato que a quantidade absoluta de matrículas ainda estava predominantemente no setor privado, com 74,9\% do total, conforme a Sinopse da Educação Superior de 2014 (INEP, 2016). Em outros termos, das 7.828.013 matrículas registradas em 2014, 5.867.011 estavam na rede privada, contra 1.961.002, ou 25,1\% das matrículas, que estavam na rede pública federal, estadual ou municipal.

Também identifica-se que os anos 2000 apresentam políticas que visam expandir as condições de acesso à educação superior e, mais especificamente, incrementar a oferta de cursos e programas destinados à formação docente, assim como indicam os dados, normativas e documentos analisados na pesquisa. Com efeito, e com base nas definições estabelecidas na Constituição Federal/1988 e na Lei de Diretrizes e Bases (LDB)/1996, mediante o regime de colaboração entre União, Estado e Município, ações no campo da educação foram estruturadas nesse modelo, como foi o caso de alguns programas de formação de professores, em especial, o Programa de Incentivo de Bolsas de Iniciação à Docência (PIBID), iniciado em 2009, que se refere ao objeto do presente estudo.

Com relação à formação de professores se verifica um incremento na oferta de cursos de licenciatura em instituições públicas de ensino superior, porém de acordo com Sinopse da Educação Superior de 2014 (INEP, 2016), que apresenta a série histórica 2005-2014, a maior concentração de matrículas se encontrava nas IES privadas, como evidencia a Tabela 2.

Tabela 2. Número de matrículas nos Cursos de Licenciatura, por categoria administrativa - 20052014.

\begin{tabular}{c|c|c|c|c|c|c}
\hline \multirow{2}{*}{ Ano } & \multirow{2}{*}{ Total } & \multicolumn{4}{|c|}{ Pública } & \multirow{2}{*}{ Privada } \\
\cline { 3 - 6 } & & Total & Federal & Estadual & Municipal & \\
\hline 2005 & 970.331 & 417.175 & 135.089 & 245.482 & 36.604 & 553.156 \\
\hline 2006 & 1.023582 & 403.525 & 130.530 & 238.237 & 34.758 & 620.057 \\
\hline 2007 & 1.062 .073 & 407.784 & 137.453 & 237.141 & 33.190 & 654.289 \\
\hline
\end{tabular}

\begin{tabular}{l|c|c|c|c|c|c} 
(C) Rev. Inter. Educ. Sup. & Campinas, SP & v.3 & n.1 & p.27-45 & jan./abr. 2017 & ISSN 2446-9424 \\
\hline
\end{tabular} 


\begin{tabular}{l|l|l|l|l|l|l}
\hline 2008 & 1.159750 & 454.086 & 159.069 & 263.955 & 31.062 & 705.664 \\
\hline 2009 & 1.191 .763 & 458.768 & 214.843 & 219.064 & 24.861 & 732.995 \\
\hline 2010 & 1.353 .989 & 561.721 & 287.322 & 249.511 & 24.888 & 793.268 \\
\hline 2011 & 1.356 .329 & 588.329 & 309.185 & 254.094 & 25.050 & 768.000 \\
\hline 2012 & 1.366 .559 & 604.483 & 322.178 & 250.843 & 31.462 & 762.076 \\
\hline 2013 & 1.374 .174 & 599.718 & 328.694 & 238.106 & 32.918 & 774.456 \\
\hline 2014 & 1.466 .635 & 604.623 & 334.688 & 240.067 & 29.868 & 862.012 \\
\hline
\end{tabular}

Fonte: INEP (2016).

A Tabela 2 mostra que no ano de 2014 as IES privadas tiveram uma maior participação nas matrículas nos cursos de Licenciatura, que representava 58,8\% do total, enquanto a rede pública participava com 41,2\%. De 2005 para 2014, o crescimento do número de matrículas nos cursos de licenciatura foi de $66,2 \%$, tendo variado positivamente em 44,9\% na rede pública; e em 55,8\% na rede privada. Estes dados revelam que embora tenha havido investimentos para expandir a oferta de cursos de licenciatura na rede pública, por meio da criação de novas instituições de ensino superior, a rede privada continua tendo o maior número de matrículas nos cursos de formação de professores.

Verifica-se, então, que a perspectiva reguladora observada nos governos Lula da Silva e Dilma Roussef, juntamente com a situação econômica de meados dos anos 2000, propiciaram o financiamento de políticas públicas voltadas para a educação superior, inclusive a implementação do PIBID, que teve como objetivo inicial contribuir para a formação de professores, contando principalmente com a atuação do ensino superior público. Para tal, concorreu o processo de expansão ocorrido entre as IES públicas na referida década.

No entanto, nota-se que, mesmo que os anos 2000 tenham apresentado maior investimento público no âmbito das políticas estatais voltadas para a educação superior, quando comparados aos anos 1990, a neoliberalização foi conservada e as relações público/privada tiveram uma importante funcionalidade, em face de um cenário de contradições postos numa organização social que tem como centro as relações de mercado.

Com base nestes elementos, o próximo tópico visa desvelar como a relação público/privada também se expressou no PIBID, nas condições postas à educação superior no Brasil, nos anos 2000 .

\section{PIBID e AS RELAÇões PÚBLICO/PRIVADAS}

Diante do cenário explicitado no tópico anterior, identifica-se que o PIBID se refere a uma ação instituída no governo Lula da Silva, que visa contribuir com o processo de melhoria da educação no país, mais especificamente no campo da formação inicial de professores. 
Constata-se que inicialmente o Programa previa apenas a participação de instituições de ensino superior públicas, porém, a partir do Edital de 2010, passou a contemplar a incorporação de instituições municipais e comunitárias, confessionais e filantrópicas sem fins lucrativos, mesmo que o programa seja desenvolvido a partir de designação de fundos públicos. E, em 2013, o Programa foi ampliado para instituições privadas com fins lucrativos (BRASIL, 2013).

A situação antes descrita associa-se à perspectiva neoliberal, a qual visa reformar o Estado de modo a diminuir sua atuação e torná-lo mais eficiente e produtivo para o mercado. Assim, com a intenção de superar a crise do capital, a concepção neoliberal incentiva a parceria público-privada, reduzindo o papel do Estado nas políticas sociais, repassando parte de suas atribuições para diferentes entes privados (PERONI et al., 2009). Desse modo, "O Poder Público não prioriza a sua função na defesa da esfera pública, delegando ao setor privado o papel de representação do público, o que, em vista disso, acarreta a privatização da esfera pública" (DOURADO, 2000, p. 283).

Figura 1. Percentuais de subprojetos apresentados ao PIBID referente ao período de 2013 e 2014, por categoria administrativa.

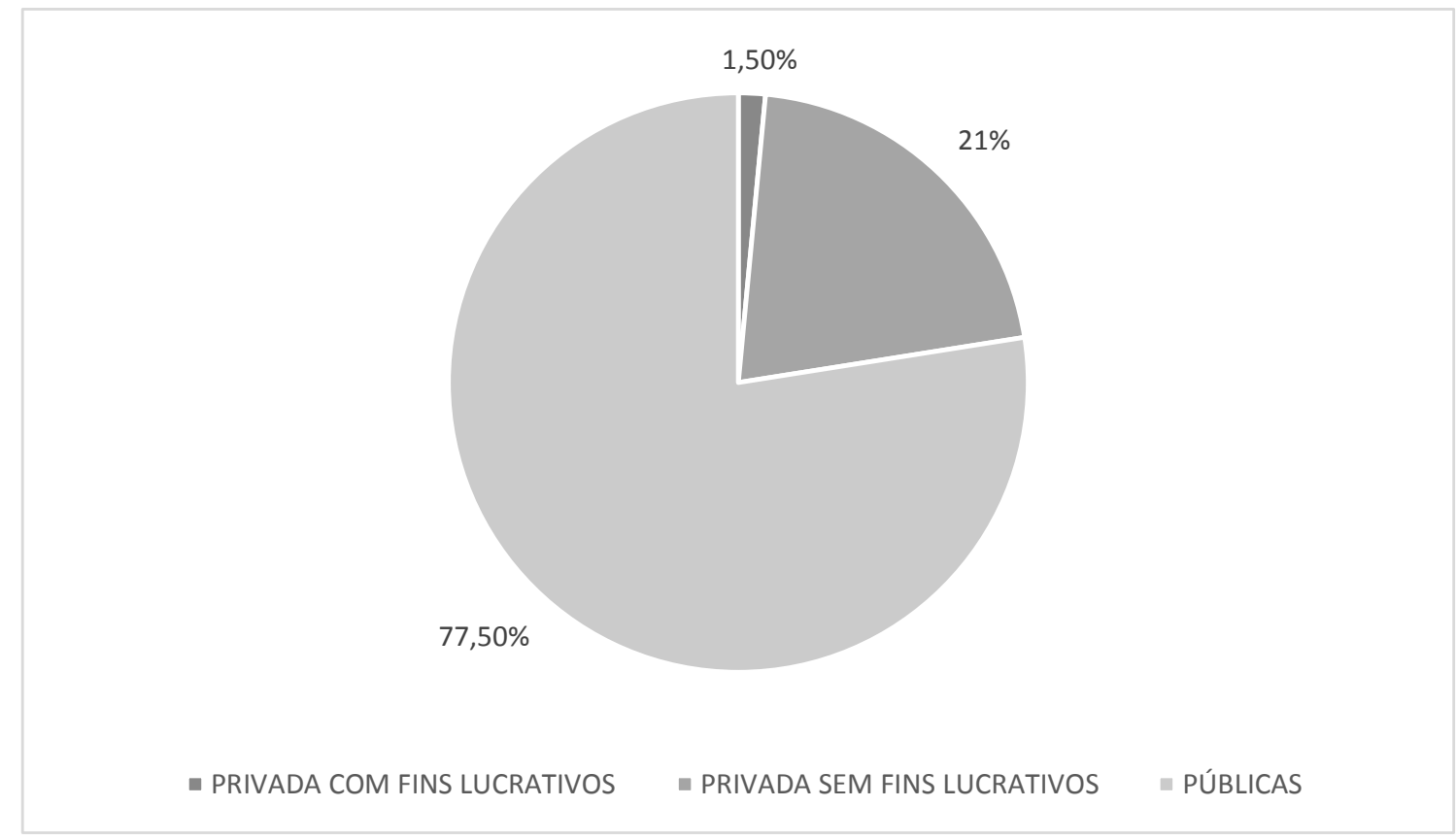

Fonte: CAPES, 2014

Organização: MACIEL, 2016.

Na Figura 1, verifica-se que o percentual de subprojetos do PIBID aprovados e consolidados nas universidades privadas com fins lucrativos, em 2013, que foram implementados a partir de 2014, foi de 1,5\%, ou ainda 45 subprojetos. Nas instituições privadas sem fins lucrativos, foram $21 \%$, ou 630 , e no setor público foram $77,5 \%$, ou 2.322 
subprojetos. De um total de 2997 subprojetos abertos, 22,5\% foram instituídos no ensino superior privado, com e sem fins lucrativos. O fato de 2013 ser o primeiro edital para as instituições privadas com fins lucrativos pode justificar o setor apresentar um percentual menor, com $1,5 \%$.

Outro aspecto que pode indicar o baixo percentual de subprojetos das IES privadas com fins lucrativos foram alguns critérios definidos pela CAPES no edital 2013, quando houve a incorporação desse setor no programa. Entre as regras previstas para execução do Programa nas instituições privadas, foi determinado que

[...] considerando o disposto na Portaria Capes n ${ }^{\circ}$ 59/2013, a Capes não repassará recursos de custeio para as IES privadas com fins lucrativos. Neste caso, os projetos executados pelas IES deverão contar com contrapartida financeira da própria instituição, no valor de $\mathrm{R} \$ 750,00$ (setecentos e cinquenta reais) por licenciando participante, até o limite de $\mathrm{R} \$ 30.000,00$ por subprojeto, por ano. (BRASIL, 2013, p. 4).

Além disso, o mesmo edital determinava que "[...] a concessão de bolsas de iniciação à docência a estudantes de licenciatura de IES privadas com fins lucrativos será limitada aos participantes do ProUni” (BRASIL, 2013, p. 3).

Essa situação implica na disposição das instituições privadas em investir financeiramente no programa para viabilizar a formação inicial para seus alunos "clientes". Com isso, evidencia-se que as condições estabelecidas para as instituições com fins lucrativos apresentavam repasses financeiros, com possíveis impactos no interesse central das empresas da educação, que é a sua lucratividade. Fato este, portanto, que pode ter contribuído para que esse setor não tivesse significativo percentual na abertura de subprojetos, assim como houve no setor público e nas instituições sem fins lucrativos.

Em outras palavras, assistia-se naquele momento ao efeito marcado, na educação, pelo empresariamento do ensino superior, assim como destaca Neves (2001) que, com relação à formação docente, vai colocar no primeiro plano a prioridade de tais empresas sobre a questão do lucro em detrimento, no caso do PIBID, à formação inicial de professores.

Considerando os dados do Inep de 2014, que apresentam uma predominância do ensino superior privado, com 74,9\% do total de matrículas (INEP, 2016) nota-se, em contrapartida, que o PIBID aponta maior prevalência no setor público, com índices de bolsas bem superiores em comparação ao ensino superior privado. Desse modo, apesar da lógica neoliberal, privatista e filantrópica ser uma tendência na conjuntura do país, e na história da implementação do PIBID com gradativas inserções do setor privado, se evidenciou, que no período de 2013 e 2014, ainda houve uma maior participação do setor público, na concessão de subprojetos. 
Simultaneamente, mesmo que tenham ocorrido mudanças nas políticas de governo a partir dos anos 2000, se verificou também continuidade, tanto nas estratégias adotadas na macroeconomia, como nas condições estabelecidas nas políticas públicas, em especial, o incentivo à participação do setor privado, acionado em parceria com o setor público. Essas ações referem-se a estratégias de manutenção do capital, inclusive desenvolvidas na implementação de programas como o PIBID.

Para ampliar a discussão sobre a implementação do Programa e a relação público/privada, cabe elucidar que o PIBID disponibiliza bolsas para todos os participantes: o coordenador institucional, coordenador de área, coordenador de gestão, supervisor e o acadêmico bolsista. Os valores dessas bolsas estão direcionados a partir das funções de cada participante do Programa. A bolsa de iniciação à docência subsidia os estudantes de licenciatura e apresenta o valor de $\mathrm{R} \$ 400,00$ (quatrocentos reais). A de supervisão, direcionadas para os professores da escola pública de educação básica, fixa um valor de $\mathrm{R} \$$ 765,00 (setecentos e sessenta e cinco reais). As bolsas de coordenação de área para os responsáveis pelos subprojetos nas licenciaturas e de coordenação de gestão que são os responsáveis pelos processos educacionais com o valor de $\mathrm{R} \$ 1.400,00$ (um mil e quatrocentos reais). E, por último, a bolsa de coordenador institucional, destinada para o professor da licenciatura que coordena o projeto PIBID nas IES, possui o valor de $\mathrm{R} \$$ 1.500,00 (um mil e quinhentos reais) (BRASIL, 2013).

Diante disso, segue a Tabela 2, que apresenta o percentual de concessão de bolsas, segundo a esfera administrativa, por região do país.

Tabela 2. Percentagem da concessão de bolsas nas instituições de ensino superior públicas e privadas, por região, entre 2013-2014.

\begin{tabular}{l|l|l|l|l|l}
\hline \multirow{2}{*}{ Especificação } & \multicolumn{2}{c|}{2013} & \multicolumn{2}{c}{2014} \\
\cline { 2 - 5 } & $\begin{array}{l}\text { Ensino Superior } \\
\text { Público }\end{array}$ & $\begin{array}{l}\text { Ensino Superior } \\
\text { Privado }\end{array}$ & $\begin{array}{l}\text { Ensino Superior } \\
\text { Público }\end{array}$ & $\begin{array}{l}\text { Ensino } \\
\text { Privado }\end{array}$ \\
\hline Centro-Oeste & 92,0 & 8,0 & 89,9 & 10,1 \\
\hline Sudeste & 88,0 & 12,0 & 71,6 & 28,4 \\
\hline Sul & 89,0 & 11,0 & 61,5 & 38,5 \\
\hline Nordeste & 85,4 & 14,6 & 97,7 & 2,3 \\
\hline Norte & 81,8 & 18,2 & 97,7 & 2,3 \\
\hline
\end{tabular}

Fonte: CAPES, 2016.

Organização: MACIEL, 2016.

A Tabela 2 aponta que, em 2013, em média, 87,2\% das bolsas distribuídas pelo PIBID foram alocadas em IES públicas, enquanto $12,3 \%$ do total ficou com as IES privadas. Para 2014, contudo, já se percebe uma tendência de aumento do número de bolsas distribuídas para o setor privado: $16,3 \%$, ou seja, um crescimento de $4,0 \%$ em relação ao ano anterior. Ao 
mesmo tempo, isso significou decréscimo de bolsas no setor público: 83,7\% em 2014, com decréscimo de 3,5\% nas concessões às IES públicas.

Com relação às regiões, nota-se que as instituições de ensino superior pública que demonstram maior percentual de expansão pela Sinopse de 2014 (INEP, 2016), também apresentam índices superiores de bolsas do PIBID entre o período de 2013 e 2014. Sendo assim, as regiões Norte e Nordeste, que apresentam os maiores valores na expansão do ensino superior público, com os percentuais em, respectivamente $18,2 \%$ e 14,6\%, registram também as maiores quantidades de bolsas do programa, ambas com $97,7 \%$.

No entanto, apesar do maior índice de concessão de bolsas para as instituições públicas se registrarem nas regiões Norte e Nordeste, em todas as outras regiões a destinação de bolsas é superior em quantidade no setor público. A região Centro-Oeste, por exemplo, mesmo que suas instituições de ensino superior tenham uma participação de apenas 8,0\% na esfera pública, as bolsas designadas a esse setor ainda atingem 89,9\%.

Nas regiões Sul e Sudeste, que indicam percentuais de 11,0\% e 12,0\%, respectivamente, nas instituições de ensino superior público, as bolsas para esse setor alcançam índices de $61,5 \%$ e $71,6 \%$. Dessa forma, o total de bolsas destinadas à esfera privada refere-se a $38,5 \%$ na região Sul e $28,4 \%$ na região Sudeste.

Mesmo que tenha ocorrido predominância na destinação de bolsas para as instituições de ensino superior pública, considera-se que os percentuais para o setor privado se expressaram crescentes e significativos, haja vista que até 2009 as bolsas eram voltadas somente para as instituições públicas, em 2010 foram inseridas as instituições de ensino superior sem fins lucrativos e, em 2013, ampliou-se a demanda para as instituições privadas com fins lucrativos, atingindo no mesmo ano um percentual de 18,0\% de bolsas para o setor privado com e sem fins lucrativos (CAPES, 2014).

Trazendo a fundo a discussão de Peroni et al. (2009), quando discutem a relação da parceria público-privada no contexto das políticas neoliberais como estratégia de superação da crise do capital, o que se percebe diante das normas da abertura de editais, dos dados do programa, juntamente à expansão do ensino superior, é que tal cenário está atrelado às iniciativas de um projeto que apresenta como centralidade reduzir o papel do Estado no âmbito do financiamento das políticas sociais e, em contrapartida, fomenta a participação privada nos ambientes, projetos e programas públicos.

No entanto, a contradição relacionada à quantidade de matrículas de licenciatura presentes nas instituições de ensino superior privada $(58,8 \%)$ e a quantidade de bolsas destinada às mesmas $(18,0 \%)$ pode ser evidenciada a partir das discussões no âmbito da educação superior trazidas por Dourado (2005) e Sguissardi (2000). Os autores abordam a falta de qualidade do ensino superior privado associada à lógica do mercado. Por conseguinte, entendem que a partir do processo de empresariamento, mercadorização e

\begin{tabular}{l|l|l|l|l|l|l|} 
(C) Rev. Inter. Educ. Sup. & Campinas, SP & v.3 & n.1 & p.27-45 & jan./abr. 2017 & ISSN 2446-9424 \\
\hline
\end{tabular}


segmentação do ensino ocorre uma tendência de dissociação entre ensino, pesquisa e extensão no ensino superior privado, com designações institucionais tipicamente de ensino.

Sobre isso, Sguissardi (2000) destaca que, ao analisar as políticas para a educação superior, é identificado o dualismo institucional da mesma, marcada pela segmentação em ensino superior universitário e não-universitário, o que acaba por naturalizar, no caso brasileiro, a hegemonia da educação superior reduzida às atividades de ensino, em detrimento das atividades de pesquisa.

Dourado (2005, p. 111) ainda reforça a discussão quando aponta a função social que o processo da indissociabilidade do tripé da educação superior (ensino, pesquisa e extensão) vem atribuir para esse nível de ensino, e o que foi provocado pelas mudanças estabelecidas nesse entendimento, principalmente a partir de 1996, com a LDB:

\begin{abstract}
Essas mudanças no campo refletiram-se na função social da educação superior: ao romper com o princípio histórico da defesa da indissociabilidade entre ensino, pesquisa e extensão; ao alterar a identidade das universidades já constituídas e consolidar a instituição de novas universidades mercantis; e, por meio de ajuste mercadológico, ao permitir a criação de centros universitários que, a despeito de gozar de algumas prerrogativas das universidades (autonomia para criar, organizar e extinguir cursos e programas, dentre outros), se caracterizam como instituições tipicamente de ensino.
\end{abstract}

Situação vinculada ao PIBID, na medida em que o programa se refere a uma proposta de formação inicial com caráter de pesquisa e extensão. Pesquisa em virtude da parceria entre universidade e escola, e extensão por ter como centralidade a formação inicial do trabalho docente na educação básica.

Sendo assim, mediante as discussões apresentadas por Dourado (2005) e Sguissardi (2000), o que se pode evidenciar é que no setor privado da educação superior há maiores indícios das instituições se caracterizarem como tipicamente de ensino, e isso pode repercutir diretamente no baixo percentual de bolsas do PIBID destinadas ao mesmo setor, quando comparado ao percentual de adesão do setor público.

Além das evidências teóricas apresentadas anteriormente, os requisitos estabelecidos pelas normas do programa podem não favorecer a maior participação das IES privadas. A disponibilidade e interesse de um professor para que um subprojeto seja aberto, por exemplo, era um requisito essencial na realização do programa; nas instituições privadas essa situação se torna mais complexa diante do cenário funcional dos professores. Diferentemente das IES públicas em que o professor trabalhador possui uma situação funcional marcada pela dedicação exclusiva, nas IES privadas o vínculo empregatício é por meio de contratação, e nem sempre em uma única IES, fato que precariza o trabalho docente e a sua disponibilidade para a realização de projetos. 
Outra circunstância que merece ser salientada refere-se aos requisitos para o aluno bolsista participar do programa. Segundo as informações no site do programa, o aluno bolsista precisava dedicar ao menos 8 (oito) horas semanais às atividades do projeto; elaborar portifólio com registros das atividades desenvolvidas; e apresentar os resultados de seu trabalho no seminário de iniciação à docência promovido pela IES, além de que nas instituições privadas com fins lucrativos a participação dos alunos no Programa está vinculada ao ingresso dos estudantes a partir do PROUNI (BRASIL, 2013). Tal situação, associada ao valor da bolsa de iniciação à docência, pode indicar dificuldades, tendo em vista que o valor da bolsa pode não suprir o custo das mensalidades dos cursos de licenciatura, e a carga horária obrigatória para se manter no programa pode dificultar os alunos a conseguirem um emprego com renda maior.

Tal questão reforçaria as desigualdades já presentes no acesso à educação superior, como lembra Freitas:

\begin{abstract}
Aos estudantes de licenciaturas, oriundos da escola pública, são concedidas bolsas PROUNI, em instituições privadas, em cursos de qualidade nem sempre desejável, ou programas de formação nos pólos municipais da Universidade Aberta do Brasil (UAB), intensificando o reforço às IES privadas, em detrimento do acolhimento massivo da juventude nas licenciaturas das instituições públicas.

Nestas instituições de ensino e pesquisa, a Bolsa Docência/CAPES espera pelos estudantes que logram vencer seus processos seletivos, visando inseri-los nas áreas de educação básica com maior carência de "professores e em escolas públicas onde os índices de desenvolvimento da educação básica (IDEBs) estão abaixo da média nacional, 3.8. (BRASIL, 2007 apud FREITAS, 2007, p. 1206).
\end{abstract}

Fazendo eco às afirmativas de Freitas (2007), ao discutir as alterações que a reforma do Estado, a partir dos anos 1990, trouxe ao ensino superior, Dourado (2005, p. 111) explicita que "[...] tais alterações implicaram, substantivamente, um processo de expansão caracterizado pela precarização da qualidade da educação e por um viés nitidamente privado", que atinge também o alunado das IES privadas, em sua grande maioria oriundos da educação básica pública. Ora, os pressupostos de um programa como o PIBID que, como dito anteriormente, baseia-se na indissociabilidade entre ensino/pesquisa/extensão, pode interferir no interesse de instituições privadas em apoiarem tal iniciativa. Este poderia ser o caso das regiões Norte e Nordeste, por exemplo, que apresentam os menores percentuais de instituições de ensino superior privado participando no PIBID, também com os menores índices de bolsas destinadas a esse setor, ambas com apenas 2,3\%.

Nota-se, então, que a parceria público-privada está pautada na estratégia neoliberal, mas também rodeada de contradições inerentes ao modo de produção capitalista. Dessa forma, as relações não são lineares e exatas, mas se apresentam em um movimento desigual e combinado. Com isso, as relações estabelecidas entre o PIBID e educação superior se constituem em uma lógica complexa, que também é perpassada pelos interesses do mercado. Simultaneamente, tem-se um programa que apresenta resultados considerados promissores

\begin{tabular}{l|l|l|l|l|l|l} 
(C) Rev. Inter. Educ. Sup. & Campinas, SP & v.3 & n.1 & p.27-45 & jan./abr. 2017 & ISSN 2446-9424 \\
\hline
\end{tabular}


como elemento para fortalecer a formação inicial dos futuros docentes, mas ao mesmo tempo tais possibilidades se entrecruzam com as demandas postas pelo sistema, dominado pelo setor privado.

\section{CONSIDERAÇÕES FINAIS}

Nota-se, a partir da história, que o PIBID e a expansão do ensino superior estão atrelados e inseridos em um contexto complexo e contraditório. Assim, apesar da expansão do ensino superior público ser evidente entre 2005 e 2014, a neoliberalização preservada na esfera de ação estatal propiciou a parceria público/privada, com destinação de recurso público ao setor privado.

Desse modo, em virtude do contexto de incentivo às políticas neoliberais que, desde 1990 se apresentou hegemônico no Brasil, até o ano de 2014 as matrículas em licenciaturas do ensino superior privado cresceram 58,8\%, em contrapartida às bolsas do PIBID que, apesar de apresentarem um viés de crescimento, estiveram em uma margem de 18,0\%. Em outras palavras, na mesma perspectiva neoliberal o PIBID, a partir dos seus editais, também aponta a parceria público/privado como uma de suas características, principalmente a partir de 2010. Fato significativo, pois no período de 2013 e 2014, a concessão de bolsas e subprojetos apresentou relevante tendência de crescimento para o setor privado, mesmo que o setor público ainda tenha demonstrado predominância.

Apesar de toda a tendência à neoliberalização, os dados apresentados demonstram um movimento contraditório na medida que o ensino superior apresenta um percentual superior referente ao total de matrículas no setor privado, e os índices de bolsas e subprojetos do PIBID, em contrapartida, indicam suas destinações em $82,0 \%$ e 77,5\%, respectivamente, para o ensino superior público.

À vista disso, diversos aspectos foram considerados e podem explicar tal situação. $\mathrm{O}$ primeiro refere-se a baixa qualidade do ensino superior, em especial do setor privado que, acordante com a lógica do mercado, realiza um processo de aligeiramento da formação do professor. Essa circunstância vai se revelar no fato de predominar, no ensino superior privado, o campo do ensino, em detrimento da pesquisa e extensão. Ora, pesquisa e extensão são dois pressupostos para a implantação do PIBID.

Outro fator apontado está vinculado ao caráter assistencialista das bolsas do Programa, que podem não favorecer o engajamento dos alunos do ensino superior privado que cursam licenciatura, e acabam por necessitar de uma renda maior do que o valor previsto com a bolsa do PIBID. 
E evidencia-se também que o PIBID apresenta um processo gradativo de inserção das diretrizes neoliberais, quando se considera que as IES privadas sem fins lucrativos ingressaram no programa em 2010, e as com fins lucrativos, em 2013. Por isso, o Programa ainda indica valores significativos de recursos públicos alocados no setor estatal, até 2014.

Sendo assim, nota-se que o Programa e a expansão do ensino superior estão inseridos em um movimento progressivo de cunho neoliberal, com parceria público/privada. Porém, as contradições estabelecidas entre o processo de expansão do ensino superior, juntamente a sua precarização, estão diretamente vinculadas às tensões ocorridas na implementação do Programa. Ambos estão conjuntamente associados a uma conjuntura neoliberal que se desenvolve por um movimento desigual, visto que as características próprias do programa estabeleceram, até 2014, alguns entraves para uma participação massiva de IES privadas, sobretudo com fins lucrativos; e combinada, visto que também se impôs para o PIBID, a parceria público-privada, com o acesso de todas as instituições, público e privadas, aos recursos do programa.

\section{REFERÊNCIAS}

BRASIL. Ministério da Educação. Decreto no 5.800, de 8 de junho de 2006. Dispõe sobre o Sistema Universidade Aberta do Brasil - UAB. Brasília: UAB, 2006c. Disponível em: <https://www.planalto.gov.br/ccivil_03/_ato2004-2006/2006/decreto/d5800.htm>. Acesso em: $21 \mathrm{dez} .2016$.

BRASIL. Ministério da Educação. Decreto n. 6.755, de 29 de janeiro de 2009. Institui a Política Nacional de Formação de Profissionais do Magistério da Educação Básica, disciplina a atuação da Coordenação de Aperfeiçoamento de Pessoal de Nível Superior, e dá outras providências. Brasília: 2009. Disponível em: <https://www.planalto.gov.br/ccivil_03/_ato 2007-2010/2009/decreto/d6755.htm>. Acesso em: 21 dez. 2016.

BRASIL. Ministério da Educação. Decreto n. 7.219, de 24 de junho de 2010. Dispõe sobre o Programa Institucional de Bolsa de Iniciação à Docência - PIBID e dá outras providências. Diário Oficial da União, Seção 1, n. 120, sexta-feira, 25 de junho de 2010. Disponível em: <http://www.capes.gov.br/images/stories/download/legislacao/Decreto7219_Pibid_240610.p df $>$. Acesso em: 20 dez. 2016.

BRASIL. Ministério de Educação. Decreto n. 8.752, de 9 de maio de 2016. Dispõe sobre a Política Nacional de Formação dos Profissionais da Educação Básica. Brasília, 2016. Disponível em: <https://www.planalto.gov.br/ccivil_03/_Ato20152018/2016/Decreto/D8752.htm\#art19>. Acesso em 21 dez. 2017.

BRASIL. Ministério da Educação. Programa de formação inicial para professores em exercício no ensino fundamental e no ensino médio: pró-licenciatura: propostas conceituais e metodológicas. Brasília: 2005. Disponível em: <http://portal.mec.gov.br/seb/arquivos/pdf /pro_licenciatura.pdf>. Acesso em: 21 dez. 2016. 
BRASIL. Ministério da Educação. Portaria normativa no 38, de 12 de dezembro DE 2007. Dispõe sobre o Programa de Bolsa Institucional de Iniciação à Docência - PIBID. Diário Oficial da União, Seção 1, n. 239, quinta-feira, 13 de dezembro de 2007. Disponível em: <https://www.capes.gov.br/images/stories/download/legislacao/Portaria_Normativa_38_PIBI D.pdf $>$. Acesso em: 20 dez. 2016.

BRASIL. Ministério da Educação. Secretaria de Articulação com os Sistemas de Ensino. Diretoria de Articulação com os Sistemas de Ensino. Relatório do Fórum de Avaliação do Financiamento da Educação Básica Nacional. Brasília: 2013. Disponível em: < http://pne.mec.gov.br/images/pdf/publicacoes/Relatorio_Forum_Avaliacao_Financiamento_E ducacao_Basica_Nacional_julho_2013.pdf>. Acesso em: 30 dez. 2016.

BRASIL. Ministério da Educação. Secretaria de Educação Básica. Orientações Gerais. Catálogo 2006. Rede Nacional de Formação Continuada de Professores de Educação Básica. Centros de Pesquisa e Desenvolvimento da Educação. Brasília: 2006. Disponível em: <http://portal.mec.gov.br/seb/arquivos/pdf/Rede/catalg_rede_06.pdf >. Acesso em: 20 dez. 2016.

BRASIL. Ministério da Educação. Secretaria do Ensino Superior. A democratização e expansão da educação superior no país (2003 - 2014). Brasília: 2014. Disponível em: $<$ http://portal.mec.gov.br/index.php?option=com_docman\&view=download\&alias=16762balanco-social-sesu-2003-2014\&Itemid=30192> . Acesso em: 3 abr. 2016.

BRASIL. Ministério da Educação. Secretaria de Ensino Superior. Programa de Consolidação das Licenciaturas. Edital n. 011/2006. Brasília: MEC, 2006b. Disponível em: <http://portal.mec.gov.br/arquivos/pdf/edital_011_2006.pdf>. Acesso em: 21 dez. 2016.

CARNEIRO, Breno Pádua Brandão; NOVAES, Ivan Luiz. Regulação do ensino superior no contexto de Contemporaneidade. In: NASCIMENTO, Antônio Dias; HETKOWSKI, Tânia Maria. (Org.). Educação e contemporaneidade: pesquisas científicas e tecnológicas [online]. Salvador: EDUFBA, 2009. p. 63-89. Disponível em: <http://books.scielo.org/id/ jc8w4/pdf/nascimento-9788523208721-04.pdf>. Acesso em: 21 mar. 2016.

\section{COORDENAÇÃO DE APERFEIÇOAMENTO DE PESSOAL DE NÍVEL SUPERIOR} (Capes). Edital n. 135, de 17 de junho de 2010. Programa de Licenciaturas Internacionais. Brasília: 2010. Disponível em: <http://www.capes.gov.br/images/stories/download/bolsas/ Edital035_LicenciaturaInternacional_Capes_UC.pdf. Acesso em: 21 dez. 2016.

\section{COORDENAÇÃO DE APERFEIÇOAMENTO DE PESSOAL DE NÍVEL SUPERIOR} (Capes). Pibid: relatórios e dados. Brasília: 2016. Disponível em: <http://www.capes.gov. br/educacao-basica/capespibid/relatorios-e-dados>. Acesso em: 5 abr. 2016.

COORDENAÇÃO DE APERFEIÇOAMENTO DE PESSOAL DE NÍVEL SUPERIOR (Capes). Diretoria de Formação de Professores da Educação Básica. Relatório de gestão: PIBID, 2013. Disponível em: <http://www.capes.gov.br/images/stories/download/bolsas/ 1892014-relatorio-PIBID.pdf.> Acesso em: 8 dez. 2015. 
COUTINHO, Luciano. A Terceira Revolução Industrial e Tecnológica: as grandes tendências de mudança. Economia e Sociedade, Campinas, n.1, p. 69-87, ago. 1992. Disponível em: <http://www3.eco.unicamp.br/publicacoes >. Acesso em: 20 mar. 2016.

DOURADO, Luiz Fernandes. O público e o privado na agenda educacional brasileira. In: AGUIAR, Márcia Angela da S.; FERREIRA, Naura Syria Carapeto (Org.). Gestão da educação: impasses, perspectivas e compromissos. São Paulo: Cortez, 2000. p. 281-292.

DOURADO, Luiz Fernandes. Reorganização dos sistemas público e privado da educação superior no Brasil. Linhas Críticas, Brasília, v. 11, n. 20, p. 103-117, jan./jun. 2005. Disponível em:<http://periodicos.unb.br/index.php/linhascriticas/article/view/5382/4486>. Acesso em: 21 jan. 2016.

FREITAS, Helena Costa Lopes de. A (nova) política de formação de professores: a prioridade postergada. Educ. Soc., Campinas, v. 28, n. 100, p. 1203-1230, out. 2007. Disponível em: <http://www.scielo.br/scielo.php?script=sci_arttext\&pid=S0101$73302007000300026 \& \operatorname{lng}=$ pt\&nrm=iso>. Acesso em: 17 maio 2016.

HARVEY, David. O neoliberalismo: história e implicações. São Paulo: Loyola, 2008.

INSTITUTO NACIONAL DE ESTUDOS E PESQUISAS ANÍSIO TEIXEIRA [INEP]. Censo da Educação Superior 2012. Brasília: 2013. Disponível em: <http://portal.mec. gov.br/index.php?option=com_docman\&view=download\&alias=14153-coletiva-censosuperior-2012\&Itemid=30192>. Acesso em: 27 mar. 2016.

INSTITUTO NACIONAL DE ESTUDOS E PESQUISAS ANÍSIO TEIXEIRA [INEP]. Censo da Educação Superior 2012. Brasília: 2013. Disponível em: <http://portal.inep. gov.br/visualizar/-/asset_publisher/6AhJ/content/resultados-de-2015-ja-podem-serconsultados-e-revelam-desafios-para-a-educacao-superiorbrasileira?redirect=http $\% 3 \mathrm{a} \% 2 \mathrm{f} \% 2 \mathrm{fportal} . \mathrm{n}_{\mathrm{n}}$ p.gov.br\%2f>. Acesso em: $22 \mathrm{dez} .2016$.

INSTITUTO NACIONAL DE ESTUDOS E PESQUISAS ANÍSIO TEIXEIRA [INEP]. Sinopse da Educação Superior 2014. Brasília: 2016. Disponível em: <http://portal.inep.gov. br/basica-censo-escolar-sinopse-sinopse>. Acesso em: 20 dez. 2016.

LEHER, Roberto. Um novo senhor da educação? A política educacional do Banco Mundial para a periferia do capitalismo. In: Revista Outubro. Revista do Instituto de Estudos Socialistas, São Paulo, n. 1, p. 19-30, 1999.

NEVES, Lúcia Maria Wanderley Neves (Org.). A nova pedagogia da hegemonia: estratégias do capital para educar o consenso. São Paulo: Xamã, 2005.

NEVES, Lúcia Maria Wanderley Neves (Org.). Direita para o social e esquerda para o capital: intelectuais da nova pedagogia da hegemonia no Brasil. São Paulo: Xamã, 2010.

NEVES, Lúcia Maria Wanderley Neves; FERNANDES, Romildo Raposo. Política Neoliberal e Educação Superior. In: NEVES, Lúcia Maria Wanderley Neves (Org.). O

n.1
p. $27-45$ jan./abr. 2017 
empresariamento da educação: novos contornos do ensino superior no Brasil dos anos 90 . São Paulo: Xamã, 2002. p. 21-40.

RUIZ Antonio Ibañez; RAMOS Mozart Neves; HINGEL, Murílio. Escassez de professores no Ensino Médio: propostas estruturais e emergenciais. Brasília: MEC/CNE/Câmara de Educação Básica, 2007. Disponível em: <http://portal.mec.gov.br/cne/arquivos/pdf/ escassez1.pdf>. Acesso em: 2 jan. 2007.

SGUISSARDI, Valdemar. (Org.). Educação superior: velhos e novos desafios. São Paulo: Xamã, 2000.

SILVEIRA, Ramaís de Castro. Neoliberalismo: conceito e influências no Brasil - de Sarney a FHC. Porto Alegre: 2009. Dissertação (Mestrado em Ciência Política) - Universidade Federal do Rio Grande do Sul. Disponível em: <http://www.lume.ufrgs.br/bitstream/ handle/10183/16218/000694385.pdf?sequence=1>. Acesso em: 15 out. 2015. 